The aim of this study was to reveal epidemiological and clinical data of the disease and discuss implemented modes of treatment.

Methods The medical records of children aged $0-5$ years hospitalized with acute gastroenteritis in our facility between 1 January 2011 and 31 December 2011 were retrieved.

Results Of 1011 patients hospitalized in the study period, 116 were rotavirus positive (11.47\%). Of all patients, $74.4 \%$ were boys and $82.75 \%$ up to one year old. The average age for patients was 16.38 months. Eutrophic were $61.12 \%$ patients, with first grade hypotrophy were $21.5 \%$ patients and with second grade hypotrophy $7.7 \%$ patients. All patients presented with diarrea, $97.41 \%$ had vomiting and $43.96 \%$ fever at the admission. $70.7 \%$ of patients had moderate dehydration and $29.3 \%$ severe dehydration. Only somewhat less than one third of the patients in study were not treated with antibiotics (36.2\%) and somewhat less then every fifteen was given blood and blood derivates (6.9\%). Every fifth patient in the study had associated disease. All patients were treated successfully.

Conclusion Rotavirus is responsible for significant portion of the acute diarrhea in Kosovo.

\section{EASY DIAGNOSTIC METHOD FOR MACRO-AST}

doi:10.1136/archdischild-2012-302724.0700

OF Beser, S Lacinel, T Erkan, FC Cokugras, T Kutlu. Istanbul University Cerrahpasa Medical Faculty, Istanbul, Turkey

Introduction Macro aspartate aminotransferase (macro-AST) has rarely reported as benign cause for increased plasma AST activities (ASAT). Highly specialized chromatography or electrophoresis were proposed for diagnosing macro-AST. We aimed to present a easy method for macro-AST.

Case Report We report here three cases of 18-month-old and 11 -year-old two girls and 5-year-old boy with an isolated chronic asymptomatic elevation of the plasma ASAT. Our patients had no relevant past medical history and no family history of liver pathologies. They have high AST levels respectively $64 \mathrm{IU} / \mathrm{L}(0-40), 123$ IU/L, 75 IU/L. They did not have hepatomegaly or splenomegaly. Several and regular controls of the liver function tests confirmed the asymptomatic isolated elevation of ASAT with values varying between 50 and $120 \mathrm{IU} / \mathrm{L}$. The viral serologies for hepatitis were always unremarkeble. ASMA, LKM, ceruloplasmine, anti-gliadin antibodies, TSH, FT4, alpha-1 antitripsin and abdominal sonographic imaging were normal. We took blood two tubes of $1 \mathrm{ml}$ of blood samples from each patients and from 3 healthy controls. We studied AST levels of one tubes and other tubes were studied after 6 days of refrigerated storage $\left(4^{\circ} \mathrm{C}\right)$. We reported $1-3 \%$ of loss of AST activity in our patients and $30-35 \%$ of loss of AST activity in control group (Table 1). As a result very low loss of AST activity of our patients supported that our patients have macro AST.

\begin{tabular}{|c|c|c|c|c|c|c|}
\hline & $\begin{array}{l}\text { 18- } \\
\text { month- } \\
\text { old }\end{array}$ & $\begin{array}{l}\text { Healthy } \\
\text { control }\end{array}$ & $\begin{array}{l}\text { 11-year- } \\
\text { old }\end{array}$ & $\begin{array}{l}\text { Healthy } \\
\text { control }\end{array}$ & 5-year-old & $\begin{array}{l}\text { Healthy } \\
\text { control }\end{array}$ \\
\hline First AST & $22010 / 2$ & 31iun & B9u/h & 2mu/h & Teith/ & $3410 / 2$ \\
\hline Second AST & maun & $2010 \mathrm{n}$ & saun & 1siuh & Trunh & zaUn \\
\hline
\end{tabular}

\section{Abstract 700 Table 1}

Conclusion Physicians should be aware of macro-AST as a cause of plasma AST activity elevations. Several laboratory techniques were proposed for diagnosing macro-AST. Some require highly specialized chromatography or electrophoresis. Other have more simple prosedures based on immunoprecipitation of macroenzymes by polyethyleneglycol. There was a simple method as we reported in our three patients.

\section{BURDEN OF ROTAVIRUS GASTROENTERITIS AMONG HOSPITALIZED INFANTS IN ROMANIA}

doi:10.1136/archdischild-2012-302724.0701

G Lesanu, RM Vlad, IF Tincu, R Smadeanu, 0 laru, I Simion, AM Teca, C Becheanu, D Pacurar. Pediatrics, 'Grigore Alexandrescu' Emergency Children's Hospital, Bucharest, Romania

Background and Aims The rotavirus infection is a major cause of acute diarrhea in young children. The study aimed to evaluate the impact on healthcare and the economic burden associated with rotavirus gastroenteritis in infants, looking at incidence, disease severity and hospitalization costs.

Methods We conducted an observational, retrospective study which included children younger than one year, hospitalized with rotavirus gastroenteritis in the Department of Pediatrics in "Grigore Alexandrescu" Emergency Children's Hospital from January until June 2011. From the medical records we extracted: month of admission, age and sex, history of the disease, clinical characteristics, data on hospital course and costs of hospital stay. Vesikari severity score was calculated for each patient (score $\geq 11$ = severe infection).

Results We selected 429 infants hospitalized with acute diarrhea from a total of 11383 patients admitted in our department. The study included 247 infants with rotavirus gastroenteritis $(2.17 \%$ of all children hospitalized). The percentage of rotavirus diarrhea was $57.6 \%$. The highest incidence of rotavirus infection was recorded in January (78\%). Mean age was 7 months and $62.3 \%$ of infants had severe diarrhea. Mean severity score was 11.3. Nosocomial infection represented $25.5 \%$ of cases. The mean duration of hospitalization was 6.4 days; the average cost for hospitalization was 581.3 euros/ patient.

Conclusions The rotavirus infection represented the etiology of acute diarrhea in more than half the cases. We report a high percentage of severe gastroenteritis and a significant percentage of nosocomial rotavirus diarrhea. The considerable medical costs should justify prevention through vaccination.

\section{THE ROLE OF ROTAVIRUS IN ACUTE GASTROENTERITIS A STUDY IN THE ISLAMIC HOSPITAL/AMMAN/JORDAN}

doi:10.1136/archdischild-2012-302724.0702

AA Almatti. Pediatrics, Islamic Hospital, Amman, Jordan

\section{Objective}

1. To study the microbial pattern of AGE in Jordan.

2. To emphasize the importance of Rota virus in the etiology of AGE.

Methods All cases of AGE admitted to our pediatric department/ Islamic hospital in 2008 were retrospectively reviewed for the results of stool tests, age, sex, duration of stay in hospital and the main symptoms.

Results A total of 1378 cases of AGE were admitted in 2008.

Confirmed diagnoses by stool testing in 570 cases (42\%)

Stool tests were negative in 784 cases (58\%)

Rotavirus cases $=485(35 \%)$

Adenovirus cases $=42(5 \%)$

Entameba histolytica cases $=35(1.5 \%)$

Bacterial (shigella sp., salmonella sp.) cases $=8(0.5 \%)$

Rotavirus was found in $85 \%$ of all stool +ve cases.

$\mathrm{M} / \mathrm{F}=1.15: 1$

Age: $<1$ year $=52 \%, 1-5$ years $=39 \%,>5$ years $=9 \%$

Mean hospital stay $=2.5$ days.

Presentations: fever (70\%), vomiting (85\%), diarrhea (96\%)

Mortality:zero\%

Conclusion AGE is a major cause of hospital admissions in Jordan. 